\title{
ARENDT E A DEMOCRACIA REPRESENTATIVA: COMENTÁRIOS INTRODUTÓRIOS
}

\section{ARENDT AND REPRESENTATIVE DEMOCRACY: INTRODUCTORY COMMENTS}

\author{
José João Neves Barbosa Vicente*
}

\begin{abstract}
RESUMO
A contribuição de Arendt ao pensamento político Ocidental é indiscutível, nesse campo, ela ocupa lugar de destaque. Seus escritos sobre a política se tornaram referências, principalmente para aqueles que buscam compreender o pensamento político contemporâneo. Com uma linguagem clara e inclinada a compreender, Arendt refletiu profundamente sobre vários assuntos em seus escritos, defendeu a liberdade e a "pluralidade humana" como essenciais à política e fez algumas considerações importantes e pertinentes sobre a democracia representativa que merecem ser divulgadas, ainda que, para alguns autores, ela não seja uma "teórica" da democracia, pelo menos como o "termo" é comumente compreendido. Neste artigo, o objetivo fundamental é destacar e apresentar de modo introdutório, alguns pontos dessas considerações como elas aprecem, por exemplo, na obra $D a$ revolução. Portanto, a proposta não é discuti-las e nem confrontá-las necessariamente com outras ideias ou teorias, mas sim apenas apresenta-las em único espaço. De um modo geral, todas essas considerações de Arendt sobre a democracia representativa presentes em sua obra, foram elaboradas por ela a partir do seu estudo sobre a Revolução Americana. Apesar de serem breves, essas considerações são imprescindíveis para o debate e a compreensão da democracia, principalmente em uma época em que a política gera muitas dúvidas e desconfianças.

PALAVRAS - CHAVE: Arendt; Liberdade; Política; Povo.
\end{abstract}

\section{ABSTRACT}

Arendt's contribution to Western political thought is indisputable, in this field, it occupies a prominent place. His writings on politics have become references, especially for those who seek to understand contemporary political thought. With clear language and inclined to understand, Arendt reflected deeply on various subjects in his writings, defended freedom and "human plurality" as essential to politics and made some important and pertinent considerations about representative democracy that deserve to be disseminated, even though, for some authors, it is not a "theoretical" of democracy, at least as the "term" is commonly understood. In this article, the fundamental objective is to highlight and present in an introductory way, some points of these considerations as they appear, for example, in the work On Revolution. Therefore, the proposal is not to discuss them or necessarily confront them with other ideas or theories, but to present them in a single space. In general, all these considerations of Arendt about representative democracy present in his work were elaborated by her from her study of the American Revolution. Although brief, these considerations are essential for the debate and understanding of democracy, especially at a time when politics generates many doubts and mistrusts.

KEYWORDS: Arendt; Freedom; Policy; People.

\footnotetext{
* Doutor em filosofia. Professor de Filosofia da Universidade Federal do Recôncavo da Bahia (UFRB). E-mail: josebvicente@bol.com.br.
}

Sapere aude - Belo Horizonte, v. 11 - n. 21, p. 70-81, Jan./Jun. 2020 - ISSN: 2177-6342 
Arendt é uma pensadora importante, e sua contribuição à teoria política, de um modo geral, é reconhecida por todos aqueles que se dedicam a esse tema, mesmo que não sejam “especialistas" no assunto. Como observou Fry (2010, p. 11, 21-22) em seus estudos sobre o pensamento da autora, a forma clara como Arendt escrevia sobre diversas questões, no intuito de compreendê-las, mas sem perder a coerência e sem uso de grandes "jargões filosóficos", fez com que suas produções intelectuais fossem apreciadas, não apenas por uma plateia meramente acadêmica, mas também pelo público em geral e pelo "recém-chegado ao seu pensamento". Sua obra como um todo, pode ser traduzida como uma resposta ao "surgimento dos regimes totalitários no século XX" que, para ela, era "o problema mais importante" e urgente da sua época. Assim, seu esforço no sentido de dar uma resposta ao totalitarismo e compreender o que havia acontecido era também uma forma de "evitar a reprodução de tal horror"; ou em outras palavras, de evitar a repetição dessa atrocidade no futuro. Isso explica a sua defesa da "importância de opiniões diferentes" e o seu esforço no sentido de "evitar a repressão do livre intercâmbio de ideias", uma prática comum em governos totalitários do século XX.

Arendt buscou, portanto, em sua obra, compreender principalmente a política, no intuito de dar uma resposta satisfatória ao totalitarismo, um regime político inimigo das opiniões e da liberdade, no qual a política se dissolveu totalmente em ideologia e terror, e os homens se tornaram seres absolutamente supérfluos, capazes de serem moldados nas formas desejadas pelo sistema e conduzidos ou guiados para qualquer lado sem muito esforço. Sem demonstrar qualquer tipo de respeito ou consideração à "pluralidade humana", o totalitarismo, "em lugar das fronteiras e dos canais de comunicação entre os homens individuais, constrói um cinturão de ferro que os cinge de tal forma que é como se a sua pluralidade se dissolvesse em Um-Só-Homem de dimensões gigantescas” (ARENDT, 1989, p. 518). Não existem limites, portanto, para as ações dos governos totalitários, uma vez que, para eles, como sublinhou Arendt em seus estudos, "tudo é possível".

É preciso destacar, no entanto, de acordo com observações de Isaac (1998, p. 100), Wolin (1994, p. 289) e Fry (2010, p. 63), que apesar da sua dedicação ao estudo minucioso da política e de nunca ter duvidado que, nesse campo, para se escapar do totalitarismo é necessário não ignorar as "múltiplas perspectivas da comunidade" e os "vários pontos de vista", Arendt jamais foi uma "teórica" da democracia, pelo menos como o termo é comumente compreendido. Ela jamais escreveu, por exemplo, um livro dedicado a esse tema e, em seus escritos, nunca abordou sistematicamente um tópico sobre a democracia. Arendt é, 
portanto, uma estudiosa de destaque no campo da política, mas não uma teórica da democracia que se dedicou sistematicamente ao estudo desse tema.

Nesse sentido, a opção de analisar neste artigo a questão da democracia representativa no pensamento de Arendt não tem qualquer pretensão de negar ou contestar as observações feitas sobre sua relação com a democracia e nem apresentá-la como uma teórica desse regime político. A opção de apresentar aqui suas ideias sobre a democracia representativa, ainda que seja de forma introdutória, tem como objetivo apenas defender que, independentemente de ter sido ou não uma "teórica" desse regime político, existem nos escritos de Arendt, principalmente em seu livro Da revolução, passagens, ainda que pequenas, nas quais ela faz algumas considerações críticas relevantes em relação à democracia representativa, com foco principalmente na democracia estabelecida nos Estados Unidos da América que merecem ser destacadas e analisadas com seriedade por aqueles que se interessam por esse tema, porque podem conter elementos importantes e indispensáveis para se pensar ou repensar esse "modelo político" de governar os homens, numa época em que a política desperta muitas dúvidas e desconfianças ao redor do mundo.

Essas considerações críticas de Arendt em relação à democracia representativa não surgiram porque ela se interessou pelo estudo da democracia em si; elas são, na verdade, frutos dos seus estudos das revoluções, principalmente da Revolução Americana. Ao analisar esse acontecimento iniciado no "verão de 1776, na Filadélfia", Arendt conclui que entre todos os esforços gigantescos dos homens no sentido de fundar um "novo corpo político", apenas a Revolução Americana foi, de fato, "coroada de êxito", apenas ela "foi bem sucedida". Em linhas gerais, o êxito ou sucesso desse evento se deve fundamentalmente à fundação de "um organismo político inteiramente novo [...] com o auxilio de uma Constituição" e ao "caráter relativamente não violento da Revolução Americana, onde a violência restringiu-se mais ou menos às atividades bélicas regulares" (ARENDT, 1972, p. 185-186). Apenas na América, portanto, a Revolução alcançou o seu verdadeiro objetivo.

Mas, apesar de a Revolução Americana ter alcançado êxito por ter fundado um novo “organismo político", Arendt sublinha que, infelizmente, esse novo corpo político fundado na América pelos homens da Revolução, "não conseguiu encontrar sua instituição apropriada" (ARENDT, 1988, p. 223). De acordo com a autora, isso aconteceu principalmente porque a forma que a "república" assumiu, não permitiu que houvesse um "espaço reservado", um "lugar apropriado" para a manifestação efetiva da liberdade dos indivíduos que inspirou os homens da Revolução. Sem um espaço no qual a ocupação por parte dos cidadãos pudesse 
ocorrer de forma ampla e efetiva, o verdadeiro exercício da liberdade política, isto é a "participação nos assuntos públicos”, se restringiu praticamente aos representantes. A efetiva participação nas deliberações públicas ficou, portanto, restrita a um pequeno número de indivíduos. Essa forma assumida pela república, consolidada nos Estados Unidos da América após a Revolução e alvo de críticas de Arendt, é a democracia representativa baseada no sistema de partidos políticos.

Para a autora, esse regime político não foi capaz de levar adiante a ideia de liberdade defendida pelos "Pais Fundadores" e que serviu para edificar essa grande nação. Esse modelo de democracia não foi capaz de criar condições para que todos tenham a oportunidade de participar efetivamente da vida política, por meio de ação e do discurso. Ação que, como entendida por Arendt, jamais pode ser representada, uma vez que somente o próprio indivíduo é capaz de desempenhá-la ou exercê-la. Como destacou em seus estudos, a única coisa que pode ser objeto de representação ou de delegação na democracia representativa é "o interesse ou o bem-estar dos outorgantes, mas não suas ações ou opiniões" (ARENDT, 1988, p. 214). A "representação", portanto, como praticada na democracia representativa, não apenas soa aos ouvidos da autora como uma noção estranha, mas também como disse Lefor (1991, p. 63-75, passim), é algo para ela "repugnante". A democracia representativa fundada no sistema de partidos políticos, não agrada Arendt, porque restringe a liberdade dos indivíduos e difículta sua efetiva participação nos assuntos públicos. Esse tipo de sistema político de governar os homens é, portanto, um sistema que destoa da forma como ela entende a política, cuja razão de ser é a liberdade.

Em sua essência, a democracia representativa como entendida por Arendt é, basicamente, um espaço onde os burocráticos eleitos representantes do povo desfrutam de privilégios. E quando a "elite burocrática" governa, o povo, de um modo geral, é privado da sua liberdade política, isto é, do seu "poder de agir". E, para a autora, como se sabe, nenhum homem é "um ser político" quando é privado da sua "faculdade para ação"; ou em outras palavras, quando é privado da sua faculdade que "o capacita a reunir-se a seus pares, a agir em concerto" (ARENDT, 2001, p. 59). Para Arendt, como observou Alves Neto (2013, p. 57), nesse tipo de regime político há um aprofundamento da "incompatibilidade entre política e liberdade", bem como um fortalecimento dos "preconceitos tradicionais sobre a política ao sediar a esfera do político no aparato do Estado". De acordo com Arendt (1988, p. 217), na democracia representativa baseada no sistema de partidos políticos, a verdadeira liberdade efetivamente não se manifesta, porque o poder do povo que "emerge da ação e deliberação 
conjugadas" encontra-se "reduzido e controlado" pelos partidos políticos que detêm o "monopólio de nomeação". Os partidos políticos são que, de fato, "indicam candidatos para cargos eletivos ou para o governo representativo"”; essa é uma das suas características fundamentais. Na verdade, "desde as suas origens", os partidos políticos sempre entenderam que "a participação do cidadão nos assuntos públicos" deveria ser "garantida por outros órgãos públicos”, ou simplesmente considerada desnecessária. Para eles, não há dúvida de que "as questões políticas" são assuntos "administrativos" que devem ser "tratados e decididos por especialistas". A democracia representativa beneficia essencialmente os partidos políticos e os representantes eleitos.

O que nesse sistema de governo é denominada de "política", diz Arendt (1988, p. 221), não passa de uma mera "profissão, uma carreira", para a qual a "elite" representante é escolhida através de "padrões e critérios que são, eles próprios, profundamente apolíticos". Com fundamentos no sistema de partidos políticos, a democracia representativa funciona como um mecanismo de exclusão do povo da vida política e cria, como observou Fine (2001, p. 122-123), enormes indiferenças em relação aos assuntos públicos. Assim, o princípio que inspirou a Revolução, isto é, a criação de um corpo político inteiramente "novo", capaz de proporcionar um espaço para a manifestação da liberdade, "não conseguiu encontrar", nem mesmo na América, "sua instituição apropriada" (ARENDT, 1988, p. 223). A democracia representativa que se estabeleceu nesse país permitiu que participassem efetivamente da política, apenas aqueles "virtuosos" que se elegem representantes. O povo tem a chance de participar politicamente, manifestar a sua opinião e exercer o seu poder, apenas nos dias da eleição; este é, portanto, o único momento em que "a antiga máxima de 'todo o poder está no povo' é verdadeira" (ARENDT, 1988, p. 189). De um modo geral, ao que se assiste hoje, em termos políticos, é uma democracia representativa que infantiliza os "cidadãos" e, frequentemente, costuma funcionar "sem nenhuma interferência do cidadão" (MCGOWAN, 1998, p. 157; DRUCKER, 2001, p. 201). Ao povo é reservada uma efetiva participação política apenas em períodos de eleições.

De acordo com as análises de Arendt, a forma como a democracia representativa se configurou constitui uma afronta ao sentido da política, porque sufoca os espaços públicos onde os homens possam agir e serem vistos em ação. Isso acontece principalmente porque o governo age simplesmente como um administrador de tarefas e não consegue se estabelecer como um corpo político capaz de assegurar o espaço para a manifestação da liberdade através 
de atos e palavras, o espaço onde os homens possam debater publicamente suas opiniões sobre assuntos que interessam a todos. Quando a política é reduzida à administração, como acontece na democracia representativa, não temos avanço, mas sim retrocesso que se traduz em obstáculo à participação política ativa. A democracia representativa é uma beneficiadora dos partidos políticos que se organizam e lutam uns contra os outros de forma feroz, em defesa dos interesses privados e de vantagens econômicas; nesse sentido, minam toda a base da esfera pública que passa a ser simplesmente um espaço de estratégias e articulações. De um modo geral, para Arendt (1988, p. 221), nesse tipo de regime político, o "relacionamento entre representante e eleitor é transformado num negócio de compra e venda"; e quando se fala em comunicação entre eles, "nunca é entre iguais, mas entre aqueles que aspiram a governar e aqueles que consentem em ser governados". Infelizmente, desde o início, o "sistema partidário", pela sua "própria natureza", sempre se inclinou a "substituir a 'fórmula governo do povo pelo povo por 'governo do povo por uma elite emanada do povo'”. Em termos arendtianos, na democracia representativa não há uma relação verdadeiramente significativa entre o indivíduo e os assuntos do governo.

Em um sistema de governo no qual não há uma efetiva participação política dos cidadãos, também não há uma efetiva liberdade. Para Arendt (1988, p. 204), em uma comunidade politicamente organizada, nenhum indivíduo é livre ou feliz se ele não participar da liberdade pública, ou em outras palavras, se não "participar, e ter uma parte, no poder público". A liberdade para a autora, como observou Rosenfeld (2010, p. 227), “envolve principalmente o domínio da política, o domínio dos assuntos humanos em geral, tal como ela foi originariamente concebida pelos gregos e seguida pelos romanos". Além de excluir a participação política de grande parte dos cidadãos, ao não garantir espaço para o debate, ou como disse Sitton (1994, p. 311), para "uma experiência política" que possibilite "opiniões bem formadas", a democracia representativa também contribui para que os indivíduos votem a partir de "interesses privados". Aos olhos de Arendt, nesse sistema de governo, a opinião, em seu sentido próprio, praticamente não existe, e a maioria das pessoas não consegue ter uma experiência de pluralidade de perspectiva. As "opiniões", como entendidas pela autora, "se formam num processo de discussão aberta e de debate público, e onde não existe oportunidade para a formação de opiniões, o que pode haver são estados de ânimo - das massas ou dos indivíduos" (ARENDT, 1988, p. 214). Na política é preciso, portanto, espaço 
onde os homens possam agir e debater livremente; sem esse espaço, não haverá formação de opiniões e nem liberdade.

Para Arendt, somos livres apenas quando agimos; e essa ação não é algo interior e nem privado, sua realização deve acontecer sempre na esfera pública e na companhia de outras pessoas. A esfera pública é o único espaço onde a liberdade pode se manifestar verdadeiramente, ela é constituída diretamente entre os homens em uma área comum através da revelação por meio de palavras e de atos. De acordo com Arendt (2009, p. 15), quando agimos estabelecemos relações diretamente uns com os outros sem qualquer "mediação das coisas ou da matéria"; exercemos nossa "condição humana da pluralidade" essencial para a vida política e reconhecemos que a Terra é habitada não por "Homem", mas sim por "homens". Na visão da autora, a democracia representativa dificulta a ação dos homens, porque o espaço para a manifestação da liberdade é reduzido ao máximo e o povo, infelizmente, não é admitido efetivamente na esfera pública; a tarefa do governo é reservada ao pequeno número de "privilegiados", apenas a esse grupo é "reservado o direito de exercitar, com exclusividade, "suas virtuosas aptidões"”. Ao povo resta apenas mergulhar profundamente "na 'letargia, que é a precursora da morte para a liberdade pública"”, ou então manter firme o seu "espírito de resistência" em relação aos governos eleitos, afinal, "o único poder que lhe resta é 'o poder residual da revolução"” (ARENDT, 1988, p. 190). A democracia representativa está longe de ser o sistema de governo que se alinha com a forma como Arendt entende a política.

De um modo geral, para Arendt, a democracia representativa é, fundamentalmente, comandada em sua totalidade por burocratas, especialistas e políticos profissionais. Nesse sentido, ela não abre suas portas à participação política da maioria e contribui para o desaparecimento de qualquer possibilidade de o povo alcançar a "felicidade pública", que passa a ser privilégio exclusivo dos seus representantes, os únicos habitantes do "espaço público", porque somente eles têm a "oportunidade de se engajar nas atividades de 'expressão, discussão e decisão', as quais, num sentido positivo, são as atividades da liberdade" (ARENDT, 1988, p. 188). Para a autora, como sublinhou Nixon (2015, p. 35), a democracia representativa privilegia "o governo da elite" eleito representante do povo, ou "uma elite burocrática" ligada aos seus partidos políticos que deixa de servir o povo que a elegeu, para defender seu próprio interesse ou o interesse do seu partido. A democracia representativa "converteu a política em monopólio de 'profissionais' da coisa pública" e, ao invés de se constituir em um verdadeiro espaço de liberdade, contribuiu em larga medida para 
eclipsá-lo. Transformou a política em uma "profissão" ocupada pelos profissionais e, consequentemente, em uma "esfera privada como outra qualquer" (D’ARCAIS, 2006, p. 1013). Ela estimula "a apatia política, o isolamento dos cidadãos e a restrição da liberdade ao instante do voto" (DUARTE, 2002, p. 61). A democracia representativa não é, portanto, para Arendt, um sistema político que proporciona espaços públicos onde todos possam exercer sua liberdade.

Arendt, como observou Amiel (1997, p. 118), se mostra extremamente preocupada com o pouco esforço que a democracia representativa faz no sentido de proteger e garantir "a ação ou a opinião do eleitor" e com as mobilizações e articulações constantes para proteger e defender a qualquer custo os interesses "da vida privada e do bem-estar pessoal". Parece que ao eleitor resta apenas exercer o seu poder de "chantagista" para pressionar seus representantes na tentativa de ser ouvido e ter seus interesses atendidos um dia. Aos olhos de Arendt (1973, p. 200), a democracia representativa reduz a capacidade do indivíduo de agir politicamente e reserva para o povo um único "espaço público”, cujo nome é a urna de votação; um lugar extremamente pequeno onde cabe apenas uma única pessoa e onde "somos, quase todos nós, nada mais que o eleitor manipulado". Esse sistema político de governar os homens diminui, portanto, a capacidade do indivíduo de aparecer na frente de seus semelhantes, para ver e ser visto em ação e palavras, para discutir e decidir, principalmente em relação à escolha de representantes que, geralmente, como disse Drucker (2001, p. 201), "uma vez no poder se entregam a todo tipo de barganha e negociação a portas fechadas. As democracias modernas são um jogo de pressões que poderia muito bem se dar, e de fato frequentemente se dá, sem nenhuma interferência dos cidadãos”. Os espaços para a efetiva ação política dos cidadãos são abertos em períodos eleitorais, eles são as urnas de votação.

Esses espaços são tão reduzidos que a participação política do povo praticamente não é sentida após a escolha dos representantes. Afinal, como observou Cansino (2006, p. 26), quem decide, de fato, são os representantes eleitos e os "partidos"; são eles que tomam decisões "nas instâncias formais de representação". Onde o espaço público é reduzido "ao mínimo instante do voto", não se pode sequer falar de uma vivência de liberdade na ação e no discurso. Assim, a democracia representativa atrofia "os espaços da liberdade, ou seja, os espaços de expressão, discussão e decisão conjunta dos cidadãos" (ALVES NETO, 2013, p. 58).

Em termos arendtianos, não existe política sem a sua razão de ser, isto é, a liberdade. E qualquer sistema político que tende a reduzir ou a controlar a manifestação dessa liberdade, 
não apenas merece contestado, mas também combatido. Para Arendt, como sublinhou Valée (2003, p. 24-25), falamos de política em seu sentido próprio "quando partilhamos o mundo com outros que são diferentes, quando debatemos e agimos com eles"; não é possível fazer política sem a "experiência "da comunidade e da reciprocidade de seres diferentes"”. A política precisa sempre levar em consideração os espaços para a manifestação da liberdade dos indivíduos e respeitar o pluralismo, as diferenças e as divergências.

Para Arendt, não se pode interferir, em hipótese alguma, na capacidade política do homem que, como disse Goldfarb (2006, p. 12), consiste essencialmente na "capacidade de aparecer e de falar na presença dos outros, de igual para igual, baseado no princípio da liberdade". Portanto, em qualquer circunstância, a política, independentemente do tipo de sistema, deve sempre respeitar o "pluralismo pleno", a "capacidade dos cidadãos para definir os conteúdos e os valores comuns", e reconhecer as diferenças e as diversidades (CANSINO, 2006, p. 26). É necessário, também, que prevaleça a garantia dos direitos civis e um "espaço de liberdade pública" onde os homens se revelam através de palavras e atos. (MCCARTHY, 2000, p. 42). A democracia representativa baseada no sistema de partidos políticos, apesar da sua promessa de liberdade e ampla participação do povo na política, aos olhos de Arendt (1988, p. 221), não representa a verdadeira defesa de espaço público acessível ao povo em geral. Na verdade, para autora, a democracia representativa não permite que "o povo qua povo" ingresse "na vida política" e se torne "participante dos negócios públicos". Basicamente, sublinha Arendt (1988, p. 115), na democracia representativa, os "direitos garantidos pelas leis", possuem todos um "caráter negativo" e nenhum deles "reivindica uma participação no governo", apenas "uma salvaguarda contra ele". São, portanto, mecanismos de controle e não de participação, e quando não há espaço para a participação ativa dos cidadãos nos assuntos públicos, corre-se o perigo de se impor uma única perspectiva.

Em termos arendtianos, não se pode defender, em hipótese alguma, uma política ou um sistema político de governar os homens que exclui ou reduz a participação política efetiva do povo. Na democracia representativa baseada no sistema de partidos políticos descrita por Arendt, de qualquer ângulo que se olhe, sempre é possível observar, não apenas a ausência da verdadeira participação política por parte do povo, mas também a ausência de uma verdadeira relação política entre ele e seus representantes ou, em outras palavras, entre a minoria que tem a oportunidade de participar dos negócios da república e a maioria que fica do lado de fora e na obscuridade. O fato incontestável é que "a liberdade de agir e de atuar politicamente" na democracia representativa existe, mas como disse Arendt (2002, p. 75), ela é uma 
"prerrogativa do governo e dos políticos profissionais que se oferecem ao povo como seus representantes no sistema de partidos”. Efetivamente, a esfera pública é constituída por esses representantes, o povo que contribui para elevá-los a essa posição, e que "teoricamente" é "a fonte e a sede do poder", permanece alijado dessa esfera. No lugar da ação política propriamente dita estão a "burocracia e a administração" que são exercidas pelos partidos políticos. Em um cenário desse tipo, o espaço público precisa ser "dominado" e controlado "por políticos ou profissionais em assuntos políticos", e "as ações e os discursos dos cidadãos" precisam ser reduzido "ao poder do voto" (BOWEN-MOORE, 1989, p. 142). A democracia representativa, portanto, como descrita por Arendt, não se encaixa em seu conceito de política, cuja razão de ser é a liberdade ${ }^{1}$.

\section{REFERÊNCIAS}

ALVES NETO, Rodrigo Ribeiro. A crítica arendtiana à democracia liberal e o sentido político da liberdade. Cadernos de ética e filosofia política. São Paulo, n. 23, p. 52-61, 2013.

AMIEL, Anne. Hannah Arendt: política e acontecimento. Tradução Sofia Mota. Lisboa: Piaget, 1997.

ARENDT, Hannah. A condição humana. Tradução Roberto Raposo. Rio de Janeiro: Forense, 2009.

ARENDT, Hannah. Crises da república. Tradução José Volkmann. São Paulo: Perspectiva, 1973.

ARENDT, Hannah. Da revolução. Tradução Fernando Dídimo Vieira. Brasília: UnB, 1988.

ARENDT, Hannah. Entre o passado e o futuro. Tradução Mauro Barbosa de Almeida. São Paulo: Perspectiva, 1972.

ARENDT, Hannah. O que é política? Tradução Reinaldo Guarany. Rio de Janeiro: Bertrand Brasil, 2002.

ARENDT, Hannah. Origens do totalitarismo: antissemitismo, imperialismo, totalitarismo. Tradução Roberto Raposo. São Paulo: Companhia das Letras, 1989.

ARENDT, Hannah. Sobre a violência. Tradução André Duarte. Rio de Janeiro: Relume Dumará, 2001.

BOWEN-MOORE, Patricia. Hannah Arendt's philosophy of natality. London: Macmillan Press, 1989.

\footnotetext{
${ }^{1} \mathrm{O}$ conteúdo deste artigo é parte da pesquisa realizada pelo autor no curso de pós-graduação na UFBA, sob a orientação do professor Dr. Genildo Ferreira da Silva.
} 
CANSINO, César. Calidad de la democracia: paradojas y contradicciones. In: ÁLVAREZ Lúcia; SAN JUAN, Carlos; MEJORADA, Cristina (coord.). Democracia y exclusión: caminos encontrados en la Ciudad de México. México, D.F.: Universidad Nacional Autónoma de México, 2006.

D'ARCAIS, Paolo Flores. Once tesissobre Hannah Arendt. Tradução Alejandro Pradera. Claves de RazónPráctica. Madrid, n. 168, p. 10-13, dez, 2006.

DRUCKER, Cláudia. O destino da tradição revolucionária: autoincompreensão ou impossibilidade ontológica? In: MORAES, Eduardo Jardim de; BIGNOTTO Newton (org.). Hannah Arendt: diálogos, reflexões, memórias. Belo Horizonte: Ed. UFMG, 2001.

DUARTE, André. Sociologia do populismo e pensamento político. In: CORREIA, Adriano (org.). Transpondo o abismo: Hannah Arendt entre a filosofia e a política. Rio de Janeiro: Forense Universitária, 2002.

FINE, Robert. Politicalinvestigations: Hegel, Marx, Arendt. London and New York: Routledge Press, 2001.

FRY, Karin. Compreender Hannah Arendt. Tradução Paulo Ferreira Valério. Petrópolis: 2010 .

GOLDFARB, Jeffrey. The politics of small things: the power of the powerless in dark times. Chicago: University of Chicago Press, 2006.

ISAAC, Jeffrey. Oases in the desert: Hannah Arendt on democracy politics. In: ISAAC, Jeffrey. Democracy in dark times. Ithaca: Cornell University Press, 1998.

LEFORT, Claude. Hannah Arendt e a questão do político. In: LEFORT, Claude. Pensando o político: ensaios sobre democracia, revolução e liberdade. Trad. Eliana M. Souza. Rio de Janeiro: Paz e Terra, 1991.

MCCARTHY, Michael. El pensamiento político de Hannah Arendt. Lima: Antonio Ruiz de Montoya, 2000.

MCGOWAN, John. Hannah Arendt: an introduction. Minneapolis: University of Minnesota Press, 1998.

NIXON, Jon. Hannah Arendt and the politics of friendship. London and New York: Bloomsbury, 2015.

ROSENFIELD, Denis. Justiça, democracia e capitalismo. Rio de Janeiro: Elsevier, 2010.

SITTON, John. Hannah Arendt's argument for council democracy. In: HINCHMAN, Lewis \& HINCHMAN, Sandra (Eds.). Hannah Arendt. Critical essays. Albany: State University of New York Press, 1994. 
VALLÉE, Catherine. Hannah Arendt: Sócrates e a questão do totalitarismo. Tradução Armando Pereira da Silva. Lisboa: Instituto Piaget, 2003.

WOLIN, Sheldon. Hannah Arendt: democracy and the political. In: HINCHMAN, Lewis \& HINCHMAN, Sandra (Eds.). Hannah Arendt. Critical essays. Albany: State University of New York Press, 1994. 